Научная статья

УДК 128

DOI: $10.18101 / 1994-0866-2021-1-25-34$

\title{
ДИАЛЕКТИКА ИНДИВИДУАЛЬНОГО И ОБЩЕСТВЕННОГО В КОНЦЕПЦИЯХ СМЫСЛА ЖИЗНИ РОССИЙСКИХ МЫСЛИТЕЛЕЙ СОВЕТСКОГО ПЕРИОДА
}

\author{
(C) Алексеева Мария Сергеевна \\ кандидат социологических наук, старший преподаватель, \\ Бурятский государственный университет имени Доржи Банзарова \\ Россия, 670000, г. Улан-Удэ, ул. Смолина, 24а \\ mashera1107@yandex.ru
}

Аннотация. В статье проанализированы основные вехи, характерные черты в изучении проблематики смысла жизни российскими учеными советского периода. В числе последних не только критика учений, находящихся вне марксистской методологии, как оторванных от реальной практики, подчиняющих личность внешним силам, но и анализ смысла жизни в контексте всестороннего развития личности при одновременной значимости социального фактора, представление смысла жизни как диалектического переплетения индивидуального и общественного, как результат рефлексивности личности и поисков, выводимых из неудовлетворенности действительностью, который воспринимается как жизненная цель и характеризуется телеономностью, интенциональностью, императивностью, обусловленностью конкретноисторическими рамками. Особое внимание уделено работам 1980-х гг., в которых получил широкое применение социологический подход, позволивший подойти более дифференцированно к изучению смысла жизни.

Ключевые слова: гедонизм; интенциональность; императивность; телеономность; иерархия целей; рефлексия: самотрансценденция; самореализация; счастье; смысл жизни.

\section{Для цитирования}

Алексеева М. С. Диалектика индивидуального и общественного в концепциях смысла жизни российских мыслителей советского периода // Вестник Бурятского государственного университета. Философия. 2021. Вып. 1. С. 25-34.

\footnotetext{
Материализовав принцип «знание - сила», люди в наше время стали стремиться в величайшей поспешности, в подлинной суете понахватать побольше знаний, приложимых к практической жизни, свидетельств, дипломов, чтобы потом мчаться дальше с той же суетливостью по поверхности жизни, не задумываясь и не углубляясь в смысл и ценность всей этой борьбы за существование, протекающей в очень тяжелых и жестоких условиях М. М. Рубинштейн
}

Исследования смысла жизни в советской России было активным уже в первые годы строительства нового социалистического общества. В 1920-е гг. вышли историко-философские очерки В. А. Поссе и М. М. Рубинштейна, «этюд из практической философии» Н. А. Рожкова. 
M. С. Алексеева. Диалектика индивидуального и общественного в концепциях смысла жизни российских мыслителей советского периода

В 1922 г. вышла, возможно, первая работа советского периода на данную тему: популярный философский очерк «В поисках смысла жизни» В. А. Поссе, в котором с критических позиций рассмотрены взгляды на смысл жизни таких философов, как Б. Спиноза, А. Шопенгауэр, И. Кант, И. Фихте, Ф. Шеллинг, Г. В. Ф. Гегель, Л. Фейербах, К. Маркс и Ф. Энгельс, М. Штирнер, Ф. Ницше, Ч. Дарвин, Э. Геккель.

В 1923 г. вышла в свет работа Н. А. Рожкова «Смысл и красота жизни: (этюд из практической философии)». Автор отмечал ошибочность концепций, где человек является «рабом слепой, бессознательной веры или игрушкой в руках сильных мира сего», отстаивая «индивидуалистическую точку зрения», сформулированную Д. И. Писаревым («...для самого себя каждое живое существо есть центр и смысл всего мироздания») и Ж. М. Гюйо («жить - значит проявлять и выражать свою личность») [7, с. 6]. Способами проявления себя являются: наука, в рамках которой человек открывает истину непосредственно, и искусство, дающее возможность открыть ее посредством красоты. И все-таки наука и искусство лишь средства для понимания жизни, для большинства, кроме самих ученых и художников, составляют лишь содержание созерцательной, не активной жизни... активность эта должна быть направлена и на самих себя, на создание из себя новых людей. <...> Величайшая из всех революций может и должна придать жизни окончательный и высший смысл и величайшую красоту. Здесь в высшем синтезе объединяется все, что осмысливает и украшает жизнь: социализм невозможен без науки, без искусства, без любви [7, с. 48, 51].

В 1927 г. выходит историко-критический очерк М. М. Рубинштейна, находящегося в эмиграции, с критикой западных и отечественных исследований смысла жизни XVIII - начала XX вв., в которых, по словам автора, «мало утешительного для решения проблемы смысла жизни личности» [8]. Основная линия критики - анализируемые концепции явно или неявно обосновывают давление высших сил над личностью, показан смысл жизни человека как части мира, но не как самодостаточной личности. Ущемление личности происходит как перед лицом природных, так и трансцендентных сил. Наиболее яркие образы в обоснование своей критики автор встречает у Г. Лейбница (человек как «духовная машина») [8, с. 49], у Вл. Соловьева (личность как средство, медиум или материал) [8, с. 112], у Г. В. Ф. Гегеля (личность как отражение воли мирового духа) $[8$, с. 97] и т. д.

Однако по-настоящему бум исследований смысла жизни в советской науке начинается с конца 1950-х гг., когда выходят работы: С. Ф. Анисимова «Наука и религия о смысле жизни»; П. И. Бокарева «О смысле и цели жизни»; Г. А. Гурева «О смысле жизни»; В. К. Комарова «О счастье и смысле жизни»; М. Н. Корнева, И. Р. Стремякова «О смысле жизни в счастье человека»; В. П. Прокофьева «Коммунистическая и религиозная этика о смысле жизни»; Ю. В. Согомонова «О смысле жизни»; О. Я. Стечкина «Развитие и представление о цели и смысле жизни в домарксистской этике»; В. Н. Чернокозовой, И. И. Чернокозова «Основы 
коммунистической морали»; В. А. Капранова «Нравственный смысл жизни и деятельности человека» и др. ${ }^{1}$

Наибольшего пика достигают публикации на данную тему в 1980-е гг. Авторы этого периода продолжают традицию критического анализа «буржуазной философии», отмечая, в частности, разделенность смысла жизни на полюса трансцендентности и повседневности, оторванность от реальной практики и даже противопоставленность ей. «Высшие цели находились за пределами собственно человеческой жизни, оставались внешними и господствующими над человеком» [1, c. 41].

Что касается личностного подхода, советские ученые как раз раскрывают проблематику смысла жизни в контексте проблем всестороннего развития социалистической личности, но раскрывают в диалектической связи частного, единичного и общего, порожденного целями общества. В качестве методологической основы - ключевые подходы к личности, сформулированные в трудах классиков марксизма-ленинизма, ссылки на которых имеются в каждой работе этого периода. «Марксистская концепция смысла человеческой жизни исходит из ее самоценности и самоцельности, однако не ограничивается только в том, чтобы смысл жизни видеть только в самой жизни, но задается вопросом «Для чего жить?» Она соединяет научное понимание жизни и человека в ней, исходящее из их объективного основания, с ценностным подходом и пониманием человека, выраженным В. И. Лениным, через «стремление реализовать себя, дать себе через себя объективность в объективном мире и осуществить (выполнить) себя» $[11$, c. 84$]$.

Такой подход представлен в работе М. С. Когана «Цель и смысл жизни человека», где личность выступает в качестве базовой теоретической категории. Всестороннее развитие личности описывается такими характеристиками, как целостность, всесторонность и гармоничность, само развитие - как ее важнейшая социальная потребность, осуществляемая через процессы самореализации и самоутверждения. Собственно, обретение смысла отражает самоопределение и самореализацию. Найдя смысл жизни, человек и находит себя самого. Так как самореализация требует активности, а она осуществляется в конкретных исторических условиях социалистического общества, то основными механизмами личностной самореализации выступают труд и творчество на благо общества. Инди-

${ }^{1}$ Анисимов С. Ф. Наука и религия о смысле жизни. М., 1964; Бокарев П. И. О смысле и цели жизни. М., 1969; Гурев Г. А. О смысле жизни. М., 1958; Комаров В. К. О счастье и смысле жизни. Волгоград, 1966; Корнев М. Н., Стремяков И. Р. О смысле жизни в счастье человека. М., 1974; Прокофьев В. П. Коммунистическая и религиозная этика о смысле жизни. М., 1973; Косенко Г. Ф. Критика религиозной концепции смысла жизни (на материалах русского православия): автореф. канд. дис. М., 1971; Согомонов Ю. В. О смысле жизни. Баку, 1964; Стечкин О. Я. Развитие и представление о цели и смысле жизни в домарксистской этике. Тула, 1971; Чернокозова В. Н., Чернокозов И. И. Основы коммунистической морали. М., 1971; Капранов В. А. Нравственный смысл жизни и деятельности человека. Л., 1975. 
M. С. Алексеева. Диалектика индивидуального и общественного в концепциях смысла жизни российских мыслителей советского периода

видуализация смысла происходит в рамках конкретизации личностью общей цели в зависимости от ее профессии и специальности [2, с. 223].

Смысл жизни рассматривается с позиций диалектики, когда личные устремления и цели могут гармонично вписываться в цели общественные, и наоборот, общественные потребности глубоко интериоризируются личностью, воспринимаются не чьими-то, не внешними, но своими собственными целями [2, с. 222]. Также в работе Б. Н. Попова смысл жизни предстает как «приобретение в труде и посредством труда своей сущности, полного развертывания своей физической и духовной энергии для блага общества и собственного счастья...» $[5$, с. 8$]$.

Н. Я. Иванова, анализируя дореволюционные концепции счастья как центральной категории для понимания смысла жизни, указала на их общие недостатки - видение счастья сугубо через личные, индивидуально замкнутые переживания и чувственные наслаждения. Счастье, как правило, выносилось за рамки гражданских устремлений и интересов, общественно-исторических потребностей и целей, а человек был «средством» и «жертвой социальности». Смысл жизни, таким образом, ошибочно воспринимался как явление сугубо духовное, не укорененное в реальной исторической практике, а личность уводилась от решения назревших социальных проблем [1, с. 154].

Общий посыл советских трактовок источников смысла жизни - общественная жизнь, общественно полезный труд, ориентация, прежде всего, на общественно значимые прогрессивные цели и интересы трудящихся, ориентация на свои силы, способности и интересы, соответственно, отрицание религиозномистических представлений о назначении человека.

Очень частый момент - ориентация на будущее счастье, счастье будущих поколений, образ светлого будущего. В то же время были и в советский период представления, несколько не вписывающиеся в этот общий каркас. Так, Г. . Гумницкий замечал, что в самой жизни и заключается смысл жизни, он не может быть найден в чем-то внешнем по отношению к жизни, не важно, окрашено ли это внешнее в светские или мистические тона [цит. по: Коган М. С., с. 220].

Социальный фактор - первостепенный для формирования смысла жизни, общественная практика и реальные общественные отношения могут как тормозить осуществление жизненных целей личности, так и способствовать их реализации. «Смысл жизни в конечном счете "задается" ей обществом» [2, с. 224]. Автор расходится с позицией Г. Н. Гумницкого, который отмечал несводимость индивидуального смысла жизни к служению общественным или даже общечеловеческим целям и идеалам [2, с. 222].

Дальнейшим развитием и конкретизацией личностной концепции смысла жизни следует назвать работы Б. Н. Попова, который рассматривает смысл жизни как результат рефлексии и неудовлетворенности своей социальной деятельностью: «Вопросы смысла жизни выражают рефлексию личности, а также психологический и моральный симптом определенной неудовлетворительности своей социальной деятельностью» [5, с. 29]. Неудовлетворенность порождает потребность. Основой смысла жизни и счастья являются потребности, а труд выступает как первая важнейшая потребность для личного и общественного блага. Именно 
эта потребность отражает стремление к самоутверждению себя как личности, и поэтому мера развития таковых есть своего рода показатель зрелости личности.

Б. Н. Попов выделил три уровня осознания смысла жизни и счастья: высокий, средний и низкий [5, с. 36]. Особое внимание уделяется низкому уровню, требующему анализа и деятельности по исправлению. Отмечается, что мещанство начинается там, где хлопоты о быте заменили главное - труд на общее благо, творчество, нравственное достоинство; быт и личное благополучие эгоистически абсолютизированы. Для мещан вопросы нравственного долга, идеалов, цели и смысла, требующие целенаправленного труда, в той мере внешние, в какой они нарушают условия бытового комфорта. Как и многие мыслители, названные выше, автор стремится отмежеваться от идеалистических трактовок смысла жизни как игнорирующих фундаментальное значение объективных, социально-экономических, отношений.

Заслугой автора является установление субординации понятий смысла жизни и счастья, не только как смежных, но и отличных, и в чем-то контрастных: «Если категория счастья фиксирует удовлетворение жизнью, то смысл жизни обусловлен наличием нереализованных потребностей и возможностями их удовлетворения» [5, с. 10].

Логическая субординация основных категорий в концепции смысла жизни Б. Н. Попова может быть представлена в следующей схеме (рис. 1):

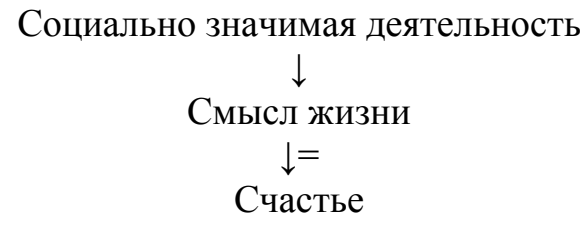

Рис. 1. Субординация основных категорий в концепции смысла жизни Б. Н. Попова

Автор опирается также и на эмпирически полученные данные, результаты опроса учащихся СПТУ нескольких районов Якутии. В числе важнейших выводов - довольно высокий процент опрошенных не имеют (или не осознают) цели как главной, определяющей основное направление их жизнедеятельности на первых курсах. Затем же, в процессе овладения специальностью, планы и цели жизни обретают определенность, конкретность. От 80 до $84 \%$ учащихся на разных курсах на вопрос о связи будущего труда и счастья, смысла жизни, ответили утвердительно [5, с. 46,63$]$.

Среди компонентов счастья и смысла жизни у опрошенных учащихся самое весомые позиции заняли: «общественная ценность своей работы», «здоровье», «взаимная любовь и дети» [5, с. 67].

Еще одним исследованием смысла жизни в советский период, где анализируемая категория была поставлена в зависимость от процессов рефлексии и самоопределения личности, ее выбора, стало исследование А. Т. Москаленко и 
M. С. Алексеева. Диалектика индивидуального и общественного в концепциях смысла жизни российских мыслителей советского периода

В. Ф. Сержантова. Нами сформулирована логическая субординация основных категорий в концепции смысла жизни данных авторов (рис. 2):

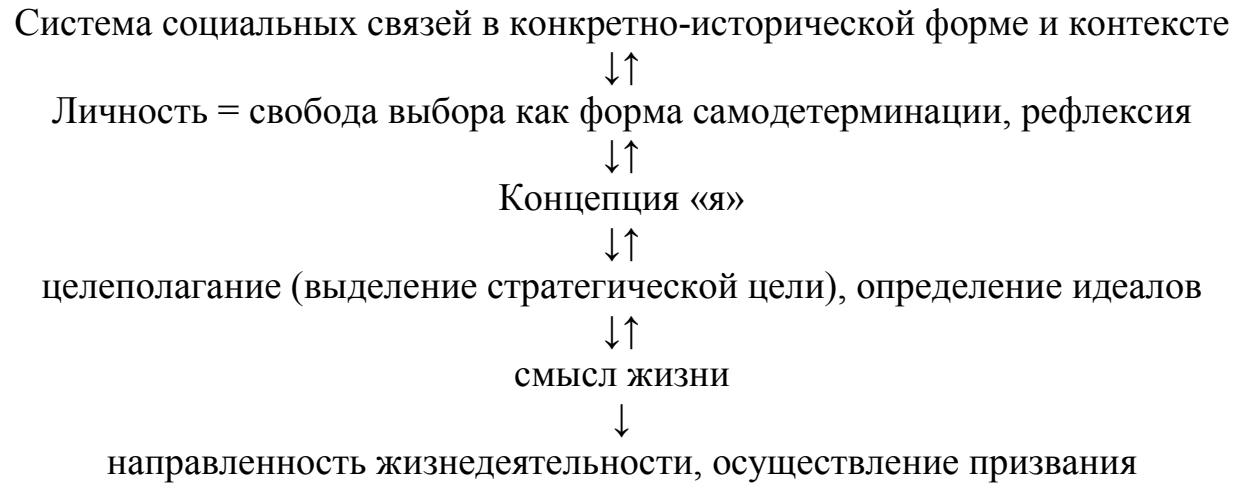

Рис. 2. Смысл жизни как фундаментальный атрибут субъекта жизни

Все поиски смысла жизни есть решение трудной проблемы: как совместить абсолютное в виде всеобщих ценностей и смысл личностного развития. Одним из вариантов разрешения проблемы является своего призвание, предназначение, находящее позитивный общественный отклик. Через идеалы служения и нравственного долга снимается проблема дихотомии смыслов для себя и для других.

В. Г. Немировский, определяя специфику социологического подхода, указывает на то, что объективная обусловленность смысла жизни личности отнюдь не является фатальной, а допускает известную свободу [4, с. 10]. Также категорию индивидуального выбора акцентировала Н. Я. Иванова: «Личность должна сделать своей жизненный выбор, а значит, это не механическое воспроизводство тех или иных социальных данностей, но акт творчества, созидания нового, неповторимого, самобытного. < ..> Выбор - это полагание личностью идеи своей жизни как главного замысла и организующего ядра, направляющего всю ее деятельность под углом единой цели» [1, с. 171].

В. Г. Немировским были выделены 9 основных концепций смысла жизни [4, c. $18-21]$ :

1. Созидательно-альтруистическая концепция. Смысл жизни в бескорыстной заботе, готовности жертвовать во имя общего блага собственными интересами.

2. Творчески-результативный подход. Смысл жизни - в созидании духовных и материальных ценностей, что дает последующее бытие в результатах своей деятельности. «Нет, весь я не умру...»

3. Социально-демографический подход: смысл жизни в рождении и воспитании потомства.

4. Игровая концепция. Смысл жизни в прогрессивном и всестороннем развитии личности. 
5. «Престижная» концепция, смысл жизни в повышении своего социального статуса, своей значимости в глазах окружающих.

6. Лидерская концепция. Смысл жизни в доминировании, утверждении власти над другими.

7. Гедонистическая концепция. Смысл жизни в получении различного рода удовольствий. В патологических случаях гипертрофированное влечение к удовольствиям принимает формы алкоголизма, наркомании, сексуальной распущенности.

8. Конформистский подход. Смысл жизни - «жить как все».

9. Теологический или религиозный подход - в соответствии с той или иной доктриной может принимать то или иное наполнение (служение Богу, бессмертие души и т. д.).

Только первые три названы автором концепциями прогрессивного общества.

Содержание, средства и время достижения жизненной цели в зависимости от разделяемой концепции смысла жизни были обобщены В. Г. Немировским в виде таблицы.

\section{Таблица 1}

Содержание, средства и время достижения жизненной цели в работе В. Г. Немировского [4, с. 25-26]

\begin{tabular}{|c|c|c|c|c|}
\hline № & $\begin{array}{l}\text { Концепции смысла } \\
\text { жизни }\end{array}$ & $\begin{array}{l}\text { Жизненная } \\
\text { цель }\end{array}$ & $\begin{array}{l}\text { Средства до- } \\
\text { стижения }\end{array}$ & $\begin{array}{l}\text { Время реали- } \\
\text { зации }\end{array}$ \\
\hline 1 & $\begin{array}{l}\text { Созидательно- } \\
\text { альтруистическая кон- } \\
\text { цепция }\end{array}$ & $\begin{array}{l}\text { Благо другого чело- } \\
\text { века }\end{array}$ & «Я» & $\begin{array}{l}\text { Жизнь, бес- } \\
\text { смертие }\end{array}$ \\
\hline 2 & Социально-творческая & $\begin{array}{l}\text { Преобразование } \\
\text { мира }\end{array}$ & «я» & $\begin{array}{l}\text { Жизнь, бес- } \\
\text { смертие }\end{array}$ \\
\hline 3 & $\begin{array}{l}\text { Социально- } \\
\text { демографическая }\end{array}$ & Воспроизводство & «я» & $\begin{array}{l}\text { Жизнь, бес- } \\
\text { смертие }\end{array}$ \\
\hline 4 & Игровая концепция & «Я» & $\begin{array}{l}\text { Люди, другой } \\
\text { человек, мир }\end{array}$ & Жизнь \\
\hline 5 & Престижная & Социальное «я» & $\begin{array}{l}\text { Другой чело- } \\
\text { век }\end{array}$ & $\begin{array}{l}\text { Жизнь, бес- } \\
\text { смертие }\end{array}$ \\
\hline 6 & Лидерская & Социальное «я» & $\begin{array}{l}\text { Другой чело- } \\
\text { век }\end{array}$ & $\begin{array}{l}\text { Жизнь, бес- } \\
\text { смертие }\end{array}$ \\
\hline 7 & Конформистская & $\begin{array}{l}\text { Социальное «я - } \\
\text { мы» }\end{array}$ & $\begin{array}{l}\text { Другой чело- } \\
\text { век, люди }\end{array}$ & Жизнь \\
\hline 8 & Гедонистическая & «я» природное & $\begin{array}{l}\text { Люди, другой } \\
\text { человек, мир }\end{array}$ & $\begin{array}{l}\text { Жизнь, бес- } \\
\text { смертие }\end{array}$ \\
\hline 9 & Религиозная & «я» духовное & $\begin{array}{l}\text { Люди, другой } \\
\text { человек, мир }\end{array}$ & Бессмертие \\
\hline
\end{tabular}

Разумеется, направленность личности и ее главная жизненная цель не являются чем-то раз и навсегда данными, неизменными. Процессульно- 
M. С. Алексеева. Диалектика индивидуального и общественного в концепциях смысла жизни российских мыслителей советского периода

мировоззренческие универсалии - рождение человека, его жизнь, смерть - характеризуют этапы и узловые точки изменения субъективного мира личности.

В. Г. Немировский опирался и на данные социологического опроса молодежи г. Красноярска (=1000), которые показали, что «стремление трудиться и приносить пользу окружающим уступает место ориентации на потребление и развлечения» [4, с. 28].

Итак, основной тренд в определении смысла жизни - это его определение как высшей цели или сверхзадачи, в которой переплетается частное и общественное. При этом авторы четко разводят понятие высшей (главной) цели и текущих целей. М. С. Коган соотносит их как «сверхзадачу» и подчиненные ей жизненные цели, отмечая, что «может возникнуть ситуация, когда целеустремленный индивид вынужден отбросить цели, препятствующие выполнению "свехзадачи"» [2, с. 228].

Перечислим наиболее типичные определения для данного периода (табл. 2):

Таблииа 2

Определения смысла жизни в трудах ученых советского периода

\begin{tabular}{|c|c|}
\hline Авторы & Определения \\
\hline М. С. Коган & $\begin{array}{l}\text { Смысл жизни - это «философская категория, отражающая } \\
\text { долговременную, устойчивую, ставшую внутренним убеждени- } \\
\text { ем личности, имеющую общественную и личную ценность за- } \\
\text { дачу*, реализующуюся в ее социальной деятельности. Эта за- } \\
\text { дача определяется системой общественных отношений... и сво- } \\
\text { бодным (в определенных границах) выбором личности» [2, } \\
\text { с. 233] }\end{array}$ \\
\hline $\begin{array}{l}\text { А. Т. Москаленко, } \\
\text { В. Ф. Сержантов }\end{array}$ & $\begin{array}{l}\text { Смысл жизни - стратегическая цель* жизни, т. е. задача на } \\
\text { длительный период или на всю жизнь, в соотнесенности с } \\
\text { надындивидуальными целями и смыслами }[3, \text { с. } 77-78]\end{array}$ \\
\hline Н. Я. Иванова & $\begin{array}{l}\text { Проблема смысла жизни личности - это проблема определе- } \\
\text { ния ею своей жизненной позиции, главной цели* жизни, при- } \\
\text { общения к революционным, исторически прогрессивным фор- } \\
\text { мам деятельности [1, с. } 171]\end{array}$ \\
\hline Б. Н. Попов & $\begin{array}{l}\text { Смысл жизни - «приобретение* в труде и посредством труда } \\
\text { своей сущности*, полного развертывания своей физической и } \\
\text { духовной энергии для блага общества и собственного сча- } \\
\text { стья...» }[5, \text { с. } 8] \text {. } \\
\text { «Смыслом жизни становится деятельность во имя* общества, } \\
\text { стремление оставить после себя жизнь, воплощенную в труде» } \\
{[5, \text { с. } 21]}\end{array}$ \\
\hline
\end{tabular}

Выделено нами. - M. $A$.

Как видим, приведенные трактовки анализируемой категории показывают смысл жизни в разных аспектах — и как феномен сознания, и как категорию деятельности, чаще же всего идет определение через цель/задачу. 
М. С. Коган акцентирует недостаточность подхода к определению смысла жизни, только как к категории сознания, т. к. определенная часть индивидов не в состоянии сформулировать смысл своей жизни. Но факт неосознанности не отменяет того, что жизнь людей тем не менее содержит смысл, т. е. категория «смысл жизни» имеет объективное содержание. «Смысл жизни заключается в объективной направленности и объективных результатах жизнедеятельности человека» [2, с. 226].

Независимо от того, декларирует ли человек своим смыслом жизни накопление и умножение вещного богатства, сама вся его жизнедеятельность может подтверждать или опровергать данную смысложизненную установку.

Итак, в трудах ученых советского периода смысл жизни отражает существенное субстанциональное (безусловное) содержание действительности, ее основание, разумную основу; соотносится с началом или действием, порождающим действительность, являющуюся ее истоком; воспринимается как жизненная цель; характеризуется телеономностью, интенциональностью; императивностью; рефлективностью, диалектическим сочетанием частного и общественного начал, обусловленностью конкретно-историческими рамками.

Литература

1. Иванова Н. Я. Философский анализ проблемы смысла бытия человека. Киев: Наукова думка, 1980. 187 с.

2. Коган М. С. Цель и смысл жизни человек. М.: Мысль, 1984. 252 с.

3. Москаленко А. Т., Сержантов В. Ф. Смысл жизни и личность. Новосибирск: Наука, 1989. 205 с.

4. Немировский В. Г. Смысл жизни: проблемы и поиски. Киев: Политиздат Украины, 1990. 223 с.

5. Попов Б. Н. Взаимосвязь категорий счастья и смысла жизни. М.: Наука, 1986. $193 \mathrm{c}$.

6. Поссе В. А. В поисках смысла жизни. Спиноза, Шопенгауер, Кант, Фихте, Шеллинг, Гегель, Фейербах, Маркс и Энгельс, Штирнер, Ницше, Дарвин, Геккель: популярный философский очерк. Воронеж, 1922. 63 с.

7. Рожков Н. А. Смысл и красота жизни: (этюд из практической философии). Петроград: типография Культпросветотдела Петрогубпрофсовета, 1923. 52 с.

8. Рубинштейн М. М. О смысле жизни. Ч. 1. Историко-критические очерки. Л.: Типография лит. журнала «Вестник Ленинградского совета». 1927. 198 с.

9. Сержантов В. Ф. Человек, его природа и смысл бытия. Л.: Изд-во Ленинград. унта, 1990.360 c.

10. Тугаринов В. П. О смысле жизни. Л.: Ленииздат, 1961. 47 с.

11. Фролов И. Т. О жизни, смерти и бессмертии. Этюды нового (реального гуманизма). Статья первая // Вопросы философии. 1983. № 1. С. 83-94.

12. Фролов И. Т. О жизни, смерти и бессмертии. Этюды нового (реального гуманизма). Статья вторая // Вопросы философии. 1983. № 2. С. 52-64.

Статья поступила в редакцию 06.02.2021; одобрена после рецензирования 08.02.2021; принята к публикации 17.02.2021. 


\title{
DIALECTICS OF INDIVIDUAL AND SOCIAL IN THE CONCEPTS OF THE MEANING OF LIFE BY RUSSIAN THINKERS OF THE SOVIET PERIOD
}

\author{
Maria S. Alekseeva \\ Cand. Sci. (Sociol.), Senior Lecturer, \\ Dorzhi Banzarov Buryat State University \\ 24a Smolina St., Ulan-Ude 670000, Russia \\ mashera1107@yandex.ru
}

Abstract. The article analyzes the main milestones in studying the problems of the meaning of life by Russian scientists of the Soviet period. It is not only a criticism of teachings that are outside of Marxist methodology, subjecting the individual to external forces, but also an analysis of the meaning of life from the perspective of individual comprehensive development with the simultaneous importance of the social factor; understanding of the meaning of life as a dialectical interweaving of the individual and the social, as a result of personal reflexivity and searches derived from dissatisfaction with reality, which perceived as a life goal, and characterized by teleonomism, intentionality, imperativeness, the concrete historical framework. Special attention we pay to the works of the 1980s, in which the sociological approach was widely used, and made it possible to apply a more differentiated approach to the study of the meaning of life.

Keywords: hedonism; intentionality; imperativeness; teleonomism; hierarchy of goals; reflection; self-transcendence; self-actualization; happiness; the meaning of life.

\section{For citation}

Alekseeva M. S. Dialectics of Individual and Social in the Concepts of the Meaning of Life by Russian Thinkers of the Soviet Period. Bulletin of Buryat State University. Philisophy. 2021; 1: 25-34 (In Russ.).

The article was submitted 06.02.2021; approved after reviewing 08.02.2021; accepted for publication 17.02.2021. 